\title{
Research on The Efficiency of Commercial Bank Branches Based on Weight-restricted DEA Model
}

\author{
Yunqiang $\mathrm{Jia}^{1, \mathrm{a},{ }^{*}}$, Xuewei $\mathrm{Li}^{1}$, Wenjun Wang $^{1}$ and Chunxin Jiang ${ }^{1}$ \\ ${ }^{1}$ School of Computer Science and Technology, Tianjin University, Tianjin 300072, China;
}

ajaky925@163.com

\begin{abstract}
Financial industry is facing unprecedented challenges, especially fierce competition between commercial banks, so it is urgent for us to solve a problem of comprehensive analysis and appropriate suggestions for the development of commercial banks. This survey uses a commercial bank's input and output data, provides an overall efficiency ranking of bank branches by calculating through the traditional DEA model $\left(\mathrm{C}^{2} \mathrm{R}\right)$, DEA Overlapping Efficiency Model and Weight-restricted DEA model. The experimental results provide the basis for understanding of each branch, which is affiliated to the commercial bank.
\end{abstract}

Keywords: Bank efficiency, DEA model, Input-output efficiency.

\section{Introduction}

Commercial banks can assess their strengths and weakness by implementing comprehensive performance evaluation of management. To promote commercial banks' competitiveness, analysis of experimental results will provide insights into assigning the limited financial resources scientifically and rationally to decision-maker. As recognized by all economists in the western theory of economics, both the definition and description of bank efficiency are the contrasting relationship between investment and yield in their business activities.

With the deepening of reform and opening up, the financial industry is facing unprecedented challenges, especially between interbank market. The question of how to achieve optimal financial resources for a single unit within the bank is a problem that needs to be addressed. Twenty years after Farrell's seminal work, and building on those ideas, Charnes et al. (1978),proposed data envelopment analysis(DEA)[1].

DEA(data envelopment analysis) Model is a commonly used method for evaluating company's operating efficiency[2]. However, the fact is that each decision unit is maximizing its efficiency rating index[3], which tends to use extreme and unreasonable weight distribution for the input and output indices, the traditional DEA method's result is somewhat unsatisfactory and cannot identify strengths and weaknesses between all the DMU. DEA Overlapping Efficiency Model partially compensates for these shortcomings of the traditional DEA method[4].

Traditional DEA model and DEA Overlapping Efficiency Model are too objective for the efficiency evaluation of commercial banks[5]. This paper provide a weight-restricted DEA model, with more subjective factors of decision ideology and value judgement. Evaluation results can be more approximates the real facts by adding the appropriate weights constraint conditions[6].

The rest of this article is organized as follows. Section 2 describes the experimental dataset of a commercial bank. Section 3 explains the models for bank efficiency and how to calculate the efficiency values of bank branches. In section 4, we show the ranking list, compare our approach results and discuss the possible causes for the ranking results. Finally, we give concluding remarks in Section 5.

\section{Datasets}

We used seventeen sub-branches’ input-output data of a commercial bank, input data include two items: number of staff, expenditure, and output data include eight items: volume of business, deposit 
and loan amount, number of public and private customers, number of credit card and debit card, income.

We pretreatment the raw data first before our experiments. That different evaluation index tend to have various unit and dimension somewhat affects the results of predictive analysis. In order to eliminate the interaction between dimension of indicators, the input-output data should be standardized. This paper takes raw data as DEA model input variables after unitary by Min-Max Normalization method.

\section{Methodology}

\subsection{DEA method of $C^{2} R$ model[7]}

Consider a set of $n$ DMUs, with each $\operatorname{DMU}_{j}(j=1,2, \ldots, n)$ using $\mathrm{m}$ inputs (consumption) $x_{i j}(i=1, \ldots, m)$ and generating $s$ outputs (cost effectiveness) $y_{r j}(r=1,2 \ldots, s)$. For $D M U \mathrm{j}$, denote $x_{i j} \in X_{j}\left(x_{1 j}, x_{2 j}, \ldots, x_{m j}\right)$ and $y_{i j} \in Y_{j}\left(y_{1 j}, y_{2 j}, \ldots, y_{r j}\right)$ the amount of input and output jth DMU invest in the commercial production. Denote $v_{i} \in V\left(v_{1}, v_{2}, \ldots, v_{m}\right)$ the weight of ith input type and $u_{r} \in U\left(u_{1}, u_{2}, \ldots, u_{s}\right)$ the weight of rth output type. In addition, $x_{i j}>0, y_{r j}>0, v_{i}>0, v_{r}>0$, $i=1,2, \ldots, m ; r=1,2, \ldots, s ; j=1,2, \ldots, n$. The total virtual input of DMU $\mathrm{j}$ is defined as $V^{T} \cdot X_{j}$ and its total virtual output is defined as $U^{T} \cdot Y_{j}$, where subscript $\mathrm{T}$ is means transposition . The $\mathrm{C}^{2} \mathrm{R}$ model (Charnes et al., 1978), measures the efficiency of DMU $\mathrm{j}$ as the maximum of the ratio of its total output to its total input: $\mathrm{h}_{\mathrm{j}}=\sum_{\mathrm{r}=1}^{\mathrm{s}} \mathrm{u}_{r} y_{r j} / \sum_{i=1}^{m} \mathrm{v}_{\mathrm{i}} x_{i j}$, endow suitable weight to make $\mathrm{h}_{\mathrm{j}} \leq 1$. Define the linear programming models of traditional DEA method $\left(C^{2} R\right)$ as follows:

$$
\begin{cases}\max Y_{i}^{\mathrm{T}} u=E_{i i}, & \\ \text { s.t. } Y_{j}^{\mathrm{T}} u-X_{j}^{\mathrm{T}} v \leq 0, & 1 \leq j \leq n, \\ X_{\mathrm{i}}^{\mathrm{T}} v=1, & u \geq 0, v \geq 0 .\end{cases}
$$

Whether the assessment of $\mathrm{DMU}_{\mathrm{j}}$ is effective or not is relative to other DMUs. If the linear programming $\mathrm{Eq}(1)$ has an optimal solution with $u^{*}>0$ and $v^{*}>0$, and the corresponding target value $E_{i i}=1$, we said $j$ th DMU is DEA efficiency, otherwise not.

\subsection{DEA Overlapping Efficiency Model[8]}

Actually, it is too inaccurate a problem to rely on the traditional DEA model, the efficiency value obtained from self-assessment cannot distinguish the strengths and weaknesses of each branch. In addition, the $\mathrm{C}^{2} \mathrm{R}$ model calculates the weights of each DMU with the most favourable, weight distribution for each input and output is extraordinary disparity, which only takes the self-interest input-output indicators into consideration and ignore other DMUs' indicators that are not to its advantage. This phenomenon makes the model reflect the merits of DMUs inaccurately.

In order to solve this problem, we introduce cross-evaluation mechanism. The principle of DEA Overlapping Efficiency Model is that using the optimal weight of each $\mathrm{DMU}_{\mathrm{i}}$ to calculate the other $\mathrm{DMU}_{\mathrm{k}}$ 's efficiency values and get cross-evaluation.

May solve directly regarding certain topics using the formula, but after some topics must carry on the ingenious distortion, can use the average value inequality solution.

The self-evaluation value $E_{i i}(1 \leq i \leq n)$ of $\mathrm{DMU}_{\mathrm{i}}$ is calculated by formula (1), given $i \in\{1,2, \ldots, n\}$, $k \in\{1,2, \ldots, n\}$.Solve the following linear equation: 


$$
\left\{\begin{array}{lr}
\min Y_{k}^{\mathrm{T}} u & \\
\text { s.t. } Y_{j}^{\mathrm{T}} u \leq X_{j}^{\mathrm{T}} v, & 1 \leq j \leq n, \\
Y_{i}^{\mathrm{T}} u=E_{i i} X_{i}^{\mathrm{T}} v, X_{i}^{\mathrm{T}} v=1, & u \geq 0, v \geq 0 .
\end{array}\right.
$$

Again, the optimal solution of formula 2 is used to find the cross-evaluation value:

$$
E_{i k}=\frac{Y_{k}^{\mathrm{T}} u_{i k}^{*}}{X_{k}^{\mathrm{T}} v_{i k}^{*}}=Y_{k}^{\mathrm{T}} u_{i k}^{*}
$$

Finally, we form the cross-evaluation matrix by cross-evaluation values:

$$
E=\left(\begin{array}{ccccc}
E_{11} & E_{12} & \cdots & E_{1 n} \\
E_{21} & E_{22} & \cdots & E_{2 n} \\
\vdots & \vdots & & \vdots \\
E_{n 1} & E_{n 2} & \cdots & E_{n n}
\end{array}\right)
$$

Which $E_{i i}$ is self-evaluation and $E_{i k}(i \neq k)$ is cross-evaluation. E's column $\mathrm{i}$ is the evaluation value of other DUMs to $\mathrm{DMU}_{\mathrm{i}}$, the higher the value is, the better $\mathrm{DMU}_{\mathrm{i}}$ is. For $\mathrm{DMU}_{\mathrm{i}}$, the strengths and weaknesses were being measured in the average value of E's column i computed as:

$$
e=\frac{1}{n} \sum_{k=1}^{n} E_{k i}
$$

$e_{i}$ is considered to be other DUMs' total assessment of $\mathrm{DMU}_{\mathrm{i}}$, the higher $e_{i}$ is , the better $\mathrm{DMU}_{\mathrm{i}}$ is, thus solving the traditional DEA's effective DMU separating problem.

\subsection{Weight-restricted DEA}

The focus of this article is Weight-restricted DEA model. After analyzing the domestic literature in existence, we find that the most of study on DEA is still using traditional DEA directly or improving DEA model, similar to DEA Overlapping Efficiency Model. Subjectively, the importance of output items causes the different weight, so some business of commercial bank should be given more attention and corresponding high weight. In order to make the result reasonable and acceptable, the major task of this paper is to add constraint weight condition to input-output data, making traditional DEA model and DEA Overlapping Efficiency Model more subjective.

If the decision-maker thinks the weight should satisfy the following t constraints:

$$
\left\{\begin{array}{l}
u_{1} y_{11}+\cdots u_{r} y_{r 1} \geq 0 \\
\cdots \cdots \cdots \cdots \cdots \cdots \cdots \cdots \cdots \cdots \cdots \cdots \cdots \cdots \cdots \cdots \cdots \\
u_{1} y_{1 t}+\cdots u_{r} y_{r t} \geq 0
\end{array}\right.
$$

In matrix form:

$$
\left(u_{1}, \cdots, u_{r}\right)\left[\begin{array}{ccc}
b_{11} & \cdots & b_{1 t} \\
\cdots & & \cdots \\
b_{r 1} & \cdots & b_{r t}
\end{array}\right] \geq 0
$$

So the DEA overlapping efficiency model with constraint conditions becomes:

$$
\left\{\begin{array}{l}
\min Y_{k}^{\mathrm{T}} u \\
\text { s.t. } Y_{j}^{\mathrm{T}} u \leq X_{j}^{\mathrm{T}} v, \\
\quad Y_{i}^{\mathrm{T}} u=E_{i i} X_{i}^{\mathrm{T}} v, X_{i}^{\mathrm{T}} v=1, \quad u \geq 0, v \geq 0, \\
\mu^{\mathrm{T}} B \geq 0 .
\end{array}\right.
$$




\section{Result and discussion}

In our work, we study sub-branches' efficiency of a commercial bank during input-output data through $C^{2} \mathrm{R}$ Model and DEA Overlapping Efficiency Model, and their results were compared. In the end, we calculate efficiency value through Weight-restricted DEA Model. Through analysis and discuss, we find that the result obtained from Weight-restricted DEA Model is reasonable and acceptable by decision-maker.

Table 1 shows the results based on $\mathrm{C}^{2} \mathrm{R}$ Model and DEA Overlapping Efficiency Model. We get a very close rank result by this two method. But compared with $\mathrm{C}^{2} \mathrm{R}$ Model, DEA Overlapping Efficiency Model is able to distinguish the strengths and weakness of DMUs.

Table1 Experiment results

\begin{tabular}{lll|lll}
\hline Sub branch & $\mathrm{C}^{2} \mathrm{R}$ & rank & Sub branch & Overlapping DEA & rank \\
\hline Branch-01 & 1 & 4 & Branch-01 & 0.70232 & 4 \\
\hline Branch-02 & 0.84810 & 16 & Branch-02 & 0.5754 & 15 \\
\hline Branch-03 & 0.89785 & 12 & Branch-03 & 0.64386 & 10 \\
\hline Branch-04 & 1 & 3 & Branch-04 & 0.74356 & 3 \\
\hline Branch-05 & 0.96776 & 10 & Branch-05 & 0.67364 & 5 \\
\hline Branch-06 & 1 & 2 & Branch-06 & 0.77095 & 2 \\
\hline Branch-07 & 0.86329 & 14 & Branch-07 & 0.54443 & 16 \\
\hline Branch-08 & 0.86848 & 13 & Branch-08 & 0.59256 & 13 \\
\hline Branch-09 & 0.90782 & 11 & Branch-09 & 0.65886 & 8 \\
\hline Branch-10 & 0.86263 & 15 & Branch-10 & 0.58366 & 14 \\
\hline Branch-11 & 1 & 8 & Branch-11 & 0.64848 & 9 \\
\hline Branch-12 & 0.71270 & 17 & Branch-12 & 0.2938 & 17 \\
\hline Branch-13 & 0.98916 & 9 & Branch-13 & 0.59882 & 12 \\
\hline Branch-14 & 1 & 6 & Branch-14 & 0.65946 & 7 \\
\hline Branch-15 & 1 & 7 & Branch-15 & 0.61969 & 11 \\
\hline Branch-16 & 1 & 1 & Branch-16 & 0.80979 & 1 \\
\hline Branch-17 & 1 & 5 & Branch-17 & 0.6698 & 6 \\
\hline
\end{tabular}

Comparison between $\mathrm{C}^{2} \mathrm{R}$ and Overlapping DEA Model as follows Fig1:

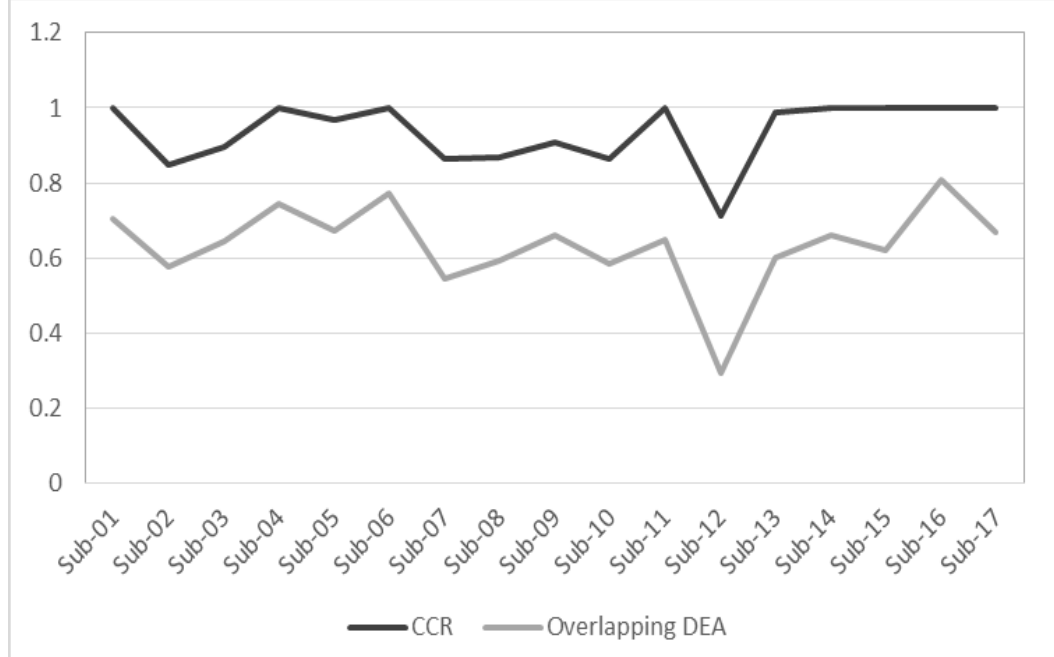

Fig 1 Comparison between CCR and Overlapping DEA Model

Table2 add the subjective conditions of decision-makers, so the result has changed, and under a certain weight constraint, efficiency and ranking has changed, but the results can reflect actual situation, and easily accepted by policy makers. 
Table2 Experiment result of Weight-restricted Model

\begin{tabular}{ccc|ccc}
\hline Sub branch & $\begin{array}{c}\text { Weight-restricted } \\
\text { Model }\end{array}$ & rank & Sub branch & $\begin{array}{c}\text { Weight-restricted } \\
\text { Model }\end{array}$ & rank \\
\hline Branch-01 & 0.271129419 & 5 & Branch-10 & 0.158526814 & 16 \\
\hline Branch-02 & 0.234492073 & 8 & Branch-11 & 0.281369014 & 4 \\
\hline Branch-03 & 0.223084928 & 9 & Branch-12 & 0.161291921 & 15 \\
\hline Branch-04 & 0.987401452 & 1 & Branch-13 & 0.559987119 & 3 \\
\hline Branch-05 & 0.234907723 & 7 & Branch-14 & 0.254511199 & 6 \\
\hline Branch-06 & 0.183182102 & 12 & Branch-15 & 0.220407608 & 10 \\
\hline Branch-07 & 0.129016028 & 17 & Branch-16 & 0.174168985 & 13 \\
\hline Branch-08 & 0.169951282 & 14 & Branch-17 & 0.783620783 & 2 \\
\hline Branch-09 & 0.206338388 & 11 & & & \\
\hline
\end{tabular}

The output data weight of table 2 result, which calculated through Weight-restricted Model, is determined by commercial bank's staff. After adding weight restriction, the rank of each branch is rearranged, the DMU with more output of high-weighted item is ranked front.

\section{Summary}

This paper proposes Weight-restricted DEA Model to compute the efficiency values of a commercial Bank's branches. We also calculate efficiency values through the traditional $C^{2} \mathrm{R}$ Model and DEA Overlapping Efficiency model. Experiments, obtained from $\mathrm{C}^{2} \mathrm{R}$ Model and Overlapping Efficiency DEA model, is very similar. Also we find that Weight-restricted DEA can better reflect the actual situation, which is consistent with our intuitive knowledge and acceptable by decision-maker.

\section{Acknowledgments}

This work was financially supported by the National Social Science Fund(15BTQ056).

\section{References}

[1] Cook W D, Seiford L M. Data envelopment analysis (DEA) - Thirty years on[J]. European Journal of Operational Research, 2009, 192(1)1-17

[2] Golany B, Roll Y. An application procedure for DEA[J]. Omega, 1989, 17(3):237-250

[3] Flokou A, Kontodimopoulos N, Niakas D. Employing post-DEA Cross-evaluation and Cluster Analysis in a Sample of Greek NHS Hospitals[J]. Journal of Medical Systems, 2011, 35(5):1001-14 [4] Peng Y W, Shou-Xian W U, Xiao-Zhan X U. DEA cross-evaluation analysis with MATLAB[J]. Journal of Southwest University for Nationalities, 2004

[5]Asmild M, Zhu M. Bank efficiency and risk during the financial crisis: Evidence from weight restricted DEA models[J]. Msap Working Paper, 2012.

[6] Chiang T A, Che Z H. A fuzzy robust evaluation model for selecting and ranking NPD projects using Bayesian belief network and weight-restricted DEA[J]. Expert Systems with Applications, 2010, 37(11):7408-7418.

[7]Opricovi? Serafim, Gwohshiung T. A comparative analysis of the DEA-CCR model and the VIKOR method[J]. Yugoslav Journal of Operations Research, 2008, 18(2):187-203.

[8] Yin H, Wang Z, Yu J, et al. Application of DEA Cross-evaluation Model in Project Dynamic Alliance Subcontractors Selection[C]// International Workshop on Intelligent Systems and Applications. IEEE, 2009:1-4. 